\title{
Secondary teachers' operationalisation of mathematical literacy
}

\author{
Oda Heidi Bolstad ${ }^{1}$ \\ ${ }^{1}$ Faculty of Humanities and Education, Volda University College, Volda, Norway \\ For correspondence: bolstado@hivolda.no
}

\begin{abstract}
:
This article reports a qualitative study of teachers' operationalisation of mathematical literacy. A model representing the multifaceted nature of mathematical literacy is used to analyse video recordings of mathematics teaching in three grade 9 classes. Analysis indicates that teachers' operationalisation of mathematical literacy appears to be fragmented and that teaching is focused on developing procedural fluency. Mathematical literacy was introduced in the Norwegian curriculum in 2006 and is considered a basic skill which should be developed across subjects. However, it appears that teachers still struggle to implement teaching to develop this competence.
\end{abstract}

Keywords: mathematical literacy, numeracy, mathematics education, teaching

\section{Introduction}

One goal of schooling is for students to acquire knowledge and competences that meet the needs of modern society. Mathematical literacy (ML) is a notion used to define the body of knowledge and competences required to meet the mathematical demands of personal and social life and to participate in society as informed, reflective, and contributing citizens (Geiger, Forgasz, \& Goos, 2015). There are several notions related to ML, for example, numeracy and quantitative literacy. While the term numeracy is more common in English-speaking countries, such as the UK, Australia, and New Zealand, quantitative literacy and ML are used in the USA (Geiger, Forgasz, et al., 2015). Some use these notions synonymously while others distinguish between them. The meaning of numeracy varies from the acquisition of basic arithmetic skills through to richer interpretations related to problem-solving in reallife contexts (Geiger, Goos, \& Forgasz, 2015). Quantitative literacy is associated with the requirements connected to the increasing influence of digital technology in society and the forms of thinking and reasoning related to problem-solving in the real world (Steen, 2001). Other perspectives, such as critical mathematical numeracy (e.g. Frankenstein, 2010), mathemacy (e.g. Skovsmose, 2011), matheracy (e.g. D'Ambrosio, 2007), are concerned with competences for challenging social injustices and for working to promote a more equitable and democratic society. Although these notions do not share the same meaning, their definitions share many common features (Goos, Geiger, \& Dole, 2014; Niss \& Jablonka, 2014).

ML is one of the competences assessed in the Programme for International Student Assessment (PISA), carried out under the auspices of the Organisation for Economic Cooperation and Development (OECD, 2012). PISA's reports that compare students' performance have been influential in shaping educational policies in several OECD countries, and curriculum developers have tried to reflect PISA competences in their national curricula (Breakspear, 2012). The first PISA results were a wake-up call for several of the participating countries. Norway, which considered itself having one of the world's best educational systems, performed (and has continued to perform) around the OECD average. 
The Norwegian "PISA shock" led to a focus on the skills required to deal with life in school, work, and society. Pupils presently at school follow the curriculum introduced in 2006 (LK06). LK06 describes ML as a basic skill "fundamental to learning in all subjects as well as a prerequisite for the student to show his/her competence and qualifications" (The Norwegian Directorate for Education and Training, 2012, p. 5). ML should be integrated and developed in all subjects across the curriculum. More specifically, LK06 states that

Numeracy means applying mathematics in different situations. Being numerate means to be able to reason and use mathematical concepts, procedures, facts and tools to solve problems and to describe, explain and predict what will happen. It involves recognizing numeracy in different contexts, asking questions related to mathematics, choosing relevant methods to solve problems and interpreting validity and effect of the results. Furthermore, it involves being able to backtrack to make new choices. Numeracy includes communicating and arguing for choices by interpreting context and working on a problem until it is solved.

Numeracy is necessary to arrive at an informed opinion about civic and social issues. Furthermore, it is equally important for personal development and the ability to make appropriate decisions in work and everyday life. (The Norwegian Directorate for Education and Training, 2012, p. 14)

This broad definition of the Norwegian basic skill is similar to the ML definition in the PISA framework (see OECD, 2012, p. 25 for comparison). Hence, the development of students' ML is a goal for mathematics teaching. Bolstad (2019) reported that Norwegian school leaders and teachers relate ML to the use-value of mathematics and the ability to use mathematics in contexts in personal, occupational and societal life. In their understanding, teaching for ML should involve practical and cross-curricular tasks and not rely too much on solving traditional textbook problems. However, the school leaders and teachers participating in the study experienced challenges in terms of finding suitable contexts in which students will experience the use-value of mathematics. Also, they do not feel competent enough to take a cross-curricular teaching approach, and the close connection between textbooks and curriculum makes it difficult to put the textbook aside.

In a similar study from Turkey, Genc and Erbas (2019) elicited seven categories related to teachers' conceptions of ML. The teachers hold various but interrelated conceptions about ML as involving 1) formal mathematical knowledge and skills, 2) conceptual understanding, 3) problem-solving skills, 4) the ability to use mathematics in everyday activities, 5) mathematical thinking, reasoning, and argumentation, 6) motivation to learn mathematics, and 7) innate mathematical ability. The various conceptions may, on the one hand, indicate an ambiguous and confusing conception of ML, or it may, on the other hand, reflect richness in one's understanding of its various aspects.

Teachers seem to recognise the contextual and applied aspect of ML. However, according to Gainsburg (2008), teachers count a wide range of practices as real-world connections. They make such connections frequently, but they are brief and does not require any thinking from the students. The study concludes that teachers' main goal is to impart mathematical concepts and skills, and the development of students' ability and disposition to recognize applications and solve real problems is of lower priority. To support ML, teachers should devise a teaching style that includes conventional and applied knowledge and create situations where formal knowledge and mathematical activities can be combined in understanding the subject matter (Höfer \& Beckmann, 2009). Steen (2001) suggests that a crosscurricular approach to ML has greater potential to empower students to meet the mathematical demands of modern life than approaches that seek to develop ML solely through mathematics subjects. A cross-curricular approach means finding other curriculum areas in which mathematics can play an important part. 
Another approach may be to draw on contexts arising from life outside school. Kaiser and Willander (2005) suggest that students should work with open problems with real-world contexts such as mathematical modelling problems to develop mathematical literacy. Modelling problems are open tasks in which students have to formulate a problem, develop a mathematical model, solve the problem, and interpret the solution in terms of mathematics and the problem context (Blum, Niss, \& Galbraith, 2007). Modelling problems have gained increasing importance in mathematics education, and mathematical modelling is considered a key process in ML in the PISA framework and the Norwegian framework for basic skills (Nordtvedt, 2013). However, everyday mathematics teaching involves few modelling activities (Blum \& Ferri, 2009). One reason may be that it makes lessons less predictable for the teacher. Teachers find it difficult to think on their feet if students give unexpected responses. Also, teachers report difficulty in anticipating students' potential responses in advance and identifying productive teaching strategies to overcome these (Jones \& Tanner, 2008). Therefore, open problems and mathematical modelling require a high level of pedagogical knowledge and skill and a willingness to explore and respond to pupils' thinking. For many teachers, this represents a challenge to current practices, especially if they have a model of teaching which is based on knowledge transmission and practicing skills (Tanner \& Jones, 2013).

A second reason for the challenge of mathematical modelling problems, which teachers experience, is that such problems require teachers' real-world knowledge. In Gainsburg's (2008) study, the teachers reported that the ideas for real-world connections mostly came from their minds and experiences. Therefore, teachers' understanding of how to apply mathematics in out-of-school contexts is an important factor for providing students with the learning experiences necessary to adapt the knowledge they learn in school to the outside world (Popovic \& Lederman, 2015).

\section{Theoretical framework}

The lack of consensus about a definition for ML and related notions makes it difficult to ensure that the same constructs are being considered. In this research, a model developed by Merrilyn Goos (see figure 1 ) is used because it is helpful in defining the complexity and scope of the domain under consideration. Goos' model is research-informed and designed to capture the richness of current definitions of ML (Goos, Geiger, \& Dole, 2010). The model represents the multifaceted nature of ML and involves five elements: mathematical knowledge, contexts, dispositions, tools, and critical orientation (i.e. Goos et al., 2014). The elements in the model are interrelated and "represent the knowledge, skills, processes, and modes of reasoning necessary to use mathematics effectively within the lived world" (Geiger, Forgasz, et al., 2015, p. 614). 


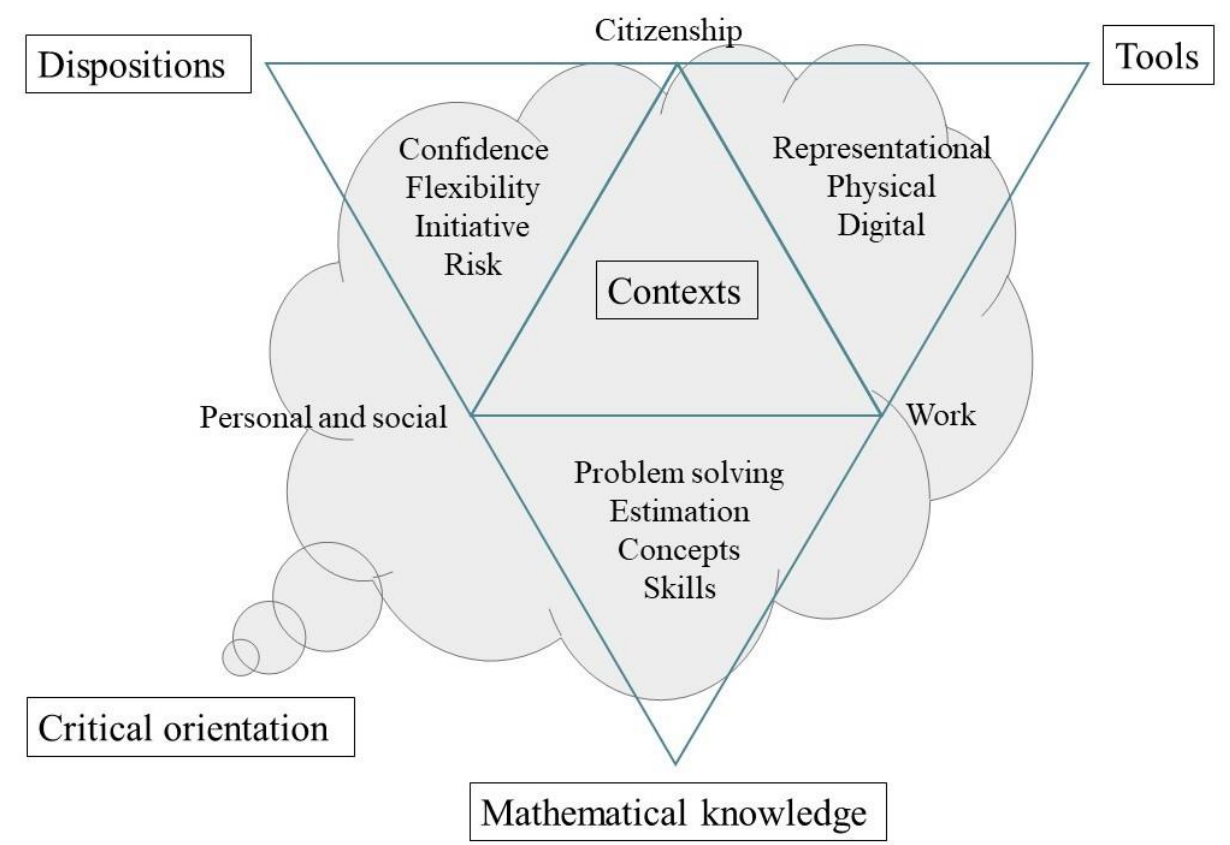

Figure 1. The multifaceted nature of ML, derived from (Goos et al., 2014)

In the following, the elements in the above model are interpreted in relation to relevant mathematics education research and in the context of teaching for ML.

\section{Mathematical knowledge}

ML requires mathematical knowledge. Researchers distinguish different kinds of mathematical knowledge. Hiebert and Lefevre (1986) discuss notions of conceptual and procedural knowledge in mathematics. Conceptual knowledge is characterised by as knowledge that is rich in relationships and connections between pieces of information. Procedural knowledge is made up of the formal language of mathematics and the algorithms and rules for completing mathematical tasks. The two notions are related to what Skemp (1976) denotes instrumental understanding, which he explains as "rules without reason", and relational understanding; knowing what to do and why.

Kilpatrick, Swafford, and Findell (2001) formulated an illustration composed of five interwoven elements, or strands, to provide a framework for discussing the mathematical knowledge, skills, abilities, and beliefs that enable students to cope with the challenges of daily life. These elements are conceptual understanding, procedural fluency, strategic competence, adaptive reasoning, and positive dispositions. I relate four of them to mathematical knowledge, although they are also involved in the other elements of ML. Conceptual understanding and procedural fluency relate to the previously mentioned concepts. Strategic competence is connected to problem-solving and refers to the ability to formulate, represent, and solve mathematical problems. Adaptive reasoning concerns thinking logically about relationships among concepts and situations. It involves knowledge of justification and validation (Kilpatrick et al., 2001).

\section{Contexts}

Numbers and data play a significant role in modern society (Steen, 2001). ML is the competence to use mathematical content in real and various contexts. The ML model highlights three contexts, personal and social, work, and citizenship. Personal and social contexts arise from daily life with the perspective of the individual being central. Such contexts may involve personal finance, making decisions about personal health, and participation in different leisure activities. Work contexts arise from professional life. According to Noss, Hoyles, and Pozzi (2000) practitioners use mathematics in their work, but what they do and how they do it may not be predictable from considerations of general mathematical 
methods. Particular occupations have specific requirements and tasks related to different kinds of mathematical knowledge, like financial transactions or drug administration. Citizenship concerns societal contexts arising from being a citizen, local, national, or global. Every major public issue depends on different types of data, for example understanding a voting system, social security funding, or international economics.

Wedege (1999) distinguishes between two kinds of contexts in mathematics activity, task context and situation context. Situation context has to do with, for example historical, social, psychological matters and relations. It is a context for learning, using and knowing mathematics (i.e. in school, everyday life, workplace), or context of mathematics education (i.e. educational system, educational policies). Task context is about representing reality in tasks, word problems, examples, textbooks, and teaching materials. In this sense, context is often normatively employed, e.g. in curriculum documents as a requirement that teaching and teaching materials shall contain "real-life context" or "meaningful and authentic contexts".

A typical way of connecting mathematics to real life is through task contexts like word problems. A word problem is a narrative that describes an artificial, pseudo-realistic situation that ends with a question requiring a number for the answer (Vos, 2018). According to Frankenstein (2010), word problems use real numerical data as "window dressing" to practice mathematical skills, and Vos (2018) argues that word problems are inauthentic and prevent students from experiencing the usefulness of mathematics. Vos proposes a model for analysing tasks concerning different aspects of authenticity; authentic methods and tools for solving the problem, authentic problem context, and authentic questions. However, authentic contexts from real life do not necessarily mean authentic questions that real people in the context would pose. Therefore, Vos highlights the importance of certification. Authenticity should be made explicit to the students. For an aspect in education to be considered as authentic, it requires an out-of-school origin that ensures that it does not originally have an educational purpose, and certification of provenance either physically or by an expert (Vos, 2018). These are important issues in analysing contexts involved in teaching for ML.

\section{Dispositions}

Dispositions are related to Kilpatrick et al.'s (2001) fifth strand, productive dispositions. To develop ML to the full requires positive dispositions towards using mathematics and an appreciation of mathematics and its benefits (Jablonka, 2003). Mathematically literate individuals possess willingness and confidence to engage with mathematics. Confidence is the opposite of "math anxiety". Empirical studies of ML show that affective factors like high anxiety and low confidence affect students' ML development (i.e. İş Güzel \& Berberoğlu, 2010; Tzohar-Rozen \& Kramarski, 2013). Also, affective factors such as self-efficacy, interest, and classroom environment influence students' ML development (Aksu \& Güzeller, 2016; Areepattamannil, 2014). People need the disposition to look at the world through mathematical eyes (Steen, 2001).

Problems occurring in everyday life usually do not come with an already existing solution. To figure out how to solve these problems requires one to think flexibly about mathematics and adapt the methods and procedures to the current context (Schoenfeld, 2001). Therefore, the competence to think creatively is an integral part of life and ML. Creativity involves taking initiative and risks.

\section{Tools}

Tools are essential in every aspect of life, for example, in communication, in education, in work life, and technology. ML concerns using mathematics as a tool to understand and uncover social and political issues. Tool use involves understanding how the use of, for example, statistical data can both deepen our understanding and change our perception of these issues (Jablonka, 2003). 
Tools are important to enable, mediate, and shape mathematical thinking and are, therefore, an important part of ML. Tools are used for some purpose to achieve something (Roth \& Radford, 2011). They can be physical items (e.g. measuring instruments or concretes), thinking tools (e.g. different forms of representations such as graphs and algebraic expressions), communicative tools (e.g. language, text, and speech), and digital tools (a calculator or computer software). They assist one to see something through something or someone else; in other words, the tools mediate. Tools can also mediate mathematical meaning. Mathematical tools help us describe, explain, and predict phenomenon, and to understand the world. Mathematics, written language, speech, gestures, and every sign system are communicative systems developed for different purposes.

\section{Critical orientation}

The model is grounded in a critical orientation to ML. ML is about recognising the powers and dangers of numbers. Mathematically literate people not only know and use efficient methods (formulate and employ), but also evaluate the results obtained (Goos et al., 2014). They evaluate mathematical solutions and reason about the context of the problem and determine whether the results are reasonable and make sense in the situation (OECD, 2012, p. 25).

Mathematically literate individuals can recognise the role mathematics plays in the world, for example, how mathematical information and practices can be used to persuade, manipulate, disadvantage, or shape opinions about social or political issues (Jablonka, 2003). In this way, ML involves the competence to use mathematics to make well-founded judgements and decisions in our personal, occupational, and societal life. Hence, mathematical reasoning is an important part of ML. To participate successfully in modern society, people need competence in ML to think through issues expressed in modern forms of communication. They also need to express themselves in these forms of communication to function as a well-educated citizen (Steen, 2001).

Frankenstein (2010) highlights the importance of understanding the meaning of numbers in real life. By using mathematics, one can illuminate how the world is structured. One can describe the world, reveal more accurate descriptions, understand the meaning of numbers used to describe, understand the implications hidden by numbers, and understand the meanings that numbers cannot convey.

The elements of the ML model can be related to the definition in the Norwegian curriculum sited in the introduction. The use of symbolic language and mathematical concepts, methods, and strategies can be related to the mathematical knowledge element. Tools for calculations, communication, and modelling relates to tools in the ML model. Contexts are described as situations in work, civic, and everyday life. Critical orientation concerns communication, validation, and evaluation of methods and solutions, and the ability to describe situations where mathematics is used. To describe and explore situations mathematically and deal with problems using mathematics also involve positive dispositions. Hence, the model can serve as a framework to analyse teaching in terms of ML in the Norwegian context. The importance of developing students' ML is recognised and prioritised internationally. Hence, the study is also of international interest.

Goos and colleagues have used the model in a series of research and development projects related to teaching ML across the curriculum (Geiger, Goos, et al., 2015). Still, few studies have used the model to analyse teaching in mathematics classrooms. If the model is suited for planning and evaluating teaching in other learning areas, it may well be suited for planning and evaluating ML in mathematics.

Even though developing students ML is deemed important, few studies have investigated teaching in this area. The purpose of this study is to investigate mathematics teaching for ML. It is believed that understanding teachers' operationalisation of ML will facilitate better support not only for students' ML development but also for teachers in terms of ongoing professional development. 
Due to the vast body of quantitative data provided by the PISA studies, research on ML is predominated by quantitative studies (Haara, Bolstad, \& Jenssen, 2017). There is, however, a lack of qualitative studies on teaching for ML, and it is argued that such research should be given priority (Haara et al., 2017; Sfard, 2014). In this article, I investigate teaching for ML in mathematics lessons. I address the following research question: How do teachers operationalise students' learning for mathematical literacy in lower secondary school mathematics classes?

In the next section, I outline the methods for data collection and my use of the model in the analysis.

\section{Method}

The research reported here is conducted within the interpretive paradigm. Social objects and categories are socially constructed and not objective facts beyond our reach and influence. Organisation and culture are products of negotiations between the parts involved, and are continually being established and renewed (Bryman, 2008). In this research, the classrooms are considered as social entities and constructions built up from the actions and perceptions of the social actors involved.

\section{Sampling and subjects}

Mathematics teachers plan and conduct teaching to enable students to obtain the goals stated in the syllabus. Teaching is influenced by the teacher's interpretation, meaning, and conceptualisation of the ideas and concepts in the curriculum and the textbook. As this study aims to investigate what teachers do in the classroom in terms of teaching for ML, data were collected through classroom observations.

Data were generated in three rural public schools in a county in Western Norway. The schools are situated in small communities where the population is homogenous in terms of cultural and social background.

The Norwegian school system is based on principles of equality of opportunity and individually adapted learning for everyone within an inclusive environment. Therefore, students are taught in mixed ability/attainment groups. The schools' total number of students on roll range from 220 to 370 and all three schools teach grades 1 through 10 . All three schools cooperate with the author's university teacher education programme. They were therefore recruited for convenience and as an outcome of acquaintance. I contacted the school leaders, and they recruited the teachers. Criteria for selection of teachers were that they were teaching grade 9 mathematics and that they agreed to participate. In Norway, grade 9 students are aged 14-15 years. As PISA measures 15 -year-olds' ML, it is reasonable to study teaching for ML to students within this age group.

To make video recordings in the classroom, I needed consent from the students and their parents. All parties involved received written information explaining my interest in studying teaching concerning concepts in policy documents. To ensure informed consent, I attended meetings with the teachers, the students and the parents. In case some students were reluctant to participate, an equivalent teaching alternative was arranged for them.

Data are composed of video recordings of classroom teaching. I observed, and video recorded three grade 9 mathematics teachers, one male and two females. I refer to the teachers as A, B, and C. Teacher A has 37 years of teaching experience and teaches mathematics, natural sciences, social studies, and Norwegian. There are 24 students in her class. Teacher B has 11 years of teaching experience. He teaches mathematics, natural sciences, and physical education. His class has 14 students. Teacher $\mathrm{C}$ has 15 years of teaching experience. In addition to mathematics, she also teaches natural sciences, social studies, religion, food and health, and arts and crafts. There are 28 students in her class. In mathematics, 
Norwegian, and English lessons, class $C$ is divided into two groups. During the fieldwork, the class was divided according to which students had consented to participate in the research. Therefore, teacher $\mathrm{C}$ had 18 students in her group during my visits.

\section{Design and procedures}

During my visits, I video recorded six mathematics lessons for teacher A, and five mathematics lessons for teachers B and C. The lessons varied in length from 45 to 90 minutes. I was a non-participant observer and did not intervene in the lessons, other than by being present. I instructed the teachers to plan and conduct the teaching as they would normally. I wanted to observe the teachers in their regular mathematics lessons.

I placed one static camera in the back of the classroom. This camera was focused toward the chalkboard but was intended to capture as much of the classroom as possible. The teacher wore a head camera. In this way, I could capture everything the teacher did and said, both to the whole group and to individual students.

Head cameras provide a unique opportunity to capture the teachers' perspective. They enable one to capture the participants' visual fields, get more in-depth insight onto the direction and timing of participant attention, and document participant actions. However, head cameras are also limited in that they can only capture a subset of participants' visual fields, potentially leaving activities underdocumented (Maltese, Danish, Bouldin, Harsh, \& Bryan, 2015). The use of head cameras is widespread in sports and studies of wildlife, but less prevalent in education research. By wearing head cameras, participants have a more active role in the data collection, and this, in a way, blurs the lines between participants and researcher (Blikstad-Balas \& Sørvik, 2015).

My presence and the cameras, the head camera, in particular, may have affected both the teachers' and the students' behaviour. However, the teachers commented on several occasions that they forgot about the cameras, even the head camera. They also said that they could not notice any changes in students' behaviour. Although there were no evident indicators, I cannot be sure that the cameras and my presence did not have any effect on the teachers' and students' behaviours. According to Blikstad-Balas (2017), the issue of reactivity is somewhat overrated when it comes to the use of video research. She claims that there is no such thing as completely "natural data" and expecting participants in a video study to pretend that nobody is recording or hiding their awareness of the camera is unnatural.

\section{Process of analysis}

I used the previously outlined elements of ML to analyse the observations to investigate teachers' operationalisation of ML. Sections of recordings were analysed and categorised to the five elements of mathematical knowledge, dispositions, context, tools, and critical orientation. To be able to identify the different elements in the classroom, I developed descriptions of what the teacher might do to address the various elements in his/her teaching.

In developing students' mathematical knowledge, the teacher can ask students to explain and discuss various solution methods, verbalise connections among representations and concepts, to represent mathematical situations in different ways, and to invent their own procedures. For computational procedures to be efficient, accurate, and correct, it is important that the teacher focuses on students' understanding, and that students get time to practice. To develop flexibility in mathematics, teachers can expose students to non-routine problems for which they do not immediately recognise a suitable solution method. Students may also benefit from a focus on several approaches to these non-routine problems. It involves urging students to explain, justify, and prove solution methods, problem solutions, and mathematical results. 
When working with tasks in context, the teacher can offer certification of authentic aspects of the task. Students could also be involved in discussing the authenticity of different aspects of the contexts. The contexts used may originate from life outside school and not originally have an educational purpose in terms of practising mathematical skills. However, the tasks can offer new insights and knowledge about the contexts in which they are situated, either real-world contexts or cross-curricular contexts.

"Developing a productive disposition requires frequent opportunities to make sense of mathematics, to recognize the benefits of perseverance, and to experience the rewards of sense making in mathematics" (Kilpatrick et al., 2001, p. 131). Teachers can encourage students to maintain positive attitudes toward mathematics. Expectations guide teachers' interactions with students. Therefore, the interaction can focus on students' capability of learning and the expectation of success. In this respect, it is important to note that success comes with hard work and learning orientation, rather than resulting from fixed abilities (Kilpatrick et al., 2001). To maintain motivation and appreciation of the value of what they are learning, teachers can help students to think about how they can apply what they are learning in different contexts. Other ways of motivating students can be to emphasise topics of student interest, communicate enthusiasm for the content, stimulate curiosity, provide opportunities to interact with peers, and introduce game-like activities.

When working with tools, it is important that the teacher helps students to see the relevant mathematical aspects involved in different tools, and makes links to concepts, symbols, and procedures. The teacher can model how tools can be used and encourage students' tool use in solving problems and tasks.

All elements are embedded in critical orientation. The teacher can engage students in activities and discussions concerning real problems. Such activities may focus on verifying, following the logic of an argument, understanding how numerical descriptions originate, using calculations to restate information, using calculations to explain information, and using calculations to reveal unstated information. To develop critical orientation, teachers can pose open-ended questions and encourage students to pose their own questions. Teachers can bring up social, political, cultural, historical, environmental, and scientific issues and help students analyse and reflect on these.

A summary of the element descriptions and operationalisations used in the analysis is displayed in table 1 below:

Table 1. Descriptions and operationalisations of the elements involved in ML

\begin{tabular}{|c|c|c|}
\hline Element & Description & Operationalisation \\
\hline $\begin{array}{l}\text { Mathematical } \\
\text { knowledge }\end{array}$ & $\begin{array}{l}\text { Mathematical concepts, skills, } \\
\text { and problem-solving strategies }\end{array}$ & $\begin{array}{l}\text { Explain and discuss methods, connect } \\
\text { concepts and representations, practice } \\
\text { skills, solve non-routine problems, } \\
\text { justify }\end{array}$ \\
\hline Contexts & $\begin{array}{l}\text { The competence to use } \\
\text { mathematical content in various } \\
\text { situations in everyday life }\end{array}$ & $\begin{array}{l}\text { Certification, authentic question, } \\
\text { authentic methods, authentic context }\end{array}$ \\
\hline Dispositions & $\begin{array}{l}\text { Willingness and confidence to } \\
\text { engage with mathematical tasks } \\
\text { flexibly and adaptively }\end{array}$ & $\begin{array}{l}\text { Encouragement, expectations, } \\
\text { enthusiasm, stimulate curiosity and } \\
\text { interest }\end{array}$ \\
\hline Tools & $\begin{array}{l}\text { The use of physical, } \\
\text { representational, and digital } \\
\text { tools to mediate and shape } \\
\text { thinking }\end{array}$ & $\begin{array}{l}\text { Model and encourage the use of } \\
\text { digital tools, representations, and } \\
\text { models }\end{array}$ \\
\hline
\end{tabular}




$$
\begin{array}{ll}
\text { Critical } & \text { To use mathematical } \\
\text { orientation } & \begin{array}{l}
\text { information to make decisions } \\
\text { and judgements, add support to } \\
\text { arguments, and challenge an } \\
\text { argument or position }
\end{array} \\
\hline
\end{array}
$$

The elements are closely connected, and teaching may focus on several elements simultaneously. Therefore, some sections were categorised to more than one element. In the following section, I present an analysis of the observations of teaching concerning the five elements.

\section{Observations}

In all of teacher A's and B's lessons, the mathematical topic is equations. Teacher $\mathrm{C}$ teaches equations for two lessons, and the remaining lessons' topic is percentages. The three teachers do not use the same textbook.

\section{Mathematical knowledge}

In the observed lessons, classroom activity usually starts with simple examples or tasks, or repetition from the previous lesson. The task difficulty increases throughout the lesson. In their lessons, the teachers prioritise developing students' procedural fluency. The following excerpt is from teacher A's lesson 2 . Writes the equation $x+7=12$ on the chalkboard.

Teacher: What do we do here? (Student 1 raises his hand) Student 1, do you want to come to the board, or do you want to dictate?

Student 1 comes to the board and solves the equation without saying anything, and then returns to his seat.

Teacher: Good stuff. Only Student 1 solved the equation in this way on the test. The same way I do it because Student 1 and I are a bit lazy. We do not write more than we have to. What has he really done? Student 2 ?

Student 2: He has subtracted on both sides.

Teacher: Yes. He has... (writes $x+7-7=12-7$ on the chalkboard) He has done this line mentally. When we have these kinds of tasks, and we are lazy, like me and Student 1 , then we think, we want the $x$ alone on one side, and move the numbers to the other side. We say, change the side, change the sign. And as I told some of you yesterday, you are going to solve the equations. Then you must show how you find the answer. You cannot do it just mentally and write only the answer.

The teacher praises Student 1 for solving the equation correctly, without asking for any explanation or justification of the procedure. Student 1 does not explain what he is doing or why while solving the equation, suggesting that this usually is not requested. Hence, the focus is on how to do it and to get the correct answer. The focus on procedures is also emphasised in the last line, where the teacher urges the students to write the whole solution on paper, even though it can easily be solved mentally, which also involves less work and is less time-consuming.

The rule "change the side, change the sign" is used by all teachers. The rule is not explained or discussed in any of the observed lessons. Teacher A consequently offers both the "lazy" method and the full solution of the equations, which might suggest that she wants the students to understand the procedure. On the other hand, the two solutions are presented as two different methods, when one of them is only a "shortcut". Also, there is no emphasis on why one subtracts the same number on both sides of the equals sign. The teachers do not demonstrate or discuss different or alternative solution 
methods, like for example, guess-and-check, and the students are not encouraged to use or look for such methods.

The lessons contain a lot of questioning and answering. The teachers ask students questions about procedures to solve the tasks, answers to calculations during task solving, and facts about concepts and procedures. Questions typically asked when starting a new task are: "What do I have to do here?", "What is the first thing I must do?", and then "What do I do next?". Why-questions are related to procedures, like "Why do I write this?". The teachers' questions are also concerned with the answers to specific calculations, such as "x plus four $\mathrm{x}$; how much is that?" (Teacher $\mathrm{A}$, lesson 1 ). The questions are closed and, therefore, limited when it comes to discussions about solution methods, connections, and justifications.

In lesson 1, teacher B focuses on developing students' strategic competence by providing a strategy for attacking word problems. It is a kind of problem-solving procedure consisting of a list of points intended to help the students structure the information given in the tasks:

1. Read the task carefully

2. Find out what they are asking for

3. Find the best point of departure (who/what do we have least knowledge of?)

4. Form the equation

5. Check if the equation makes sense

6. Solve the equation to find the unknown

7. See if you have the answer to the task

The teacher refers to this list when they solve word problems and encourages the students to use it as well. Students are set to practice solving word problems individually or in pairs to practice their strategic competence. However, it seems that the preferred solution method is equations.

Another example of strategic competence is the rule, "change the side and change the sign". Demonstrating this rule is showing that one can replace or simplify initial procedures with more effective procedures, and this is part of having strategic competence. However, if the rule is not understood, and demonstrated without justification, it is pure instrumental knowledge.

The teachers work to develop conceptual understanding by helping students to draw on previous knowledge. For example, when working with equations with fractions, teacher B's students struggle solving them. The teacher writes the following on the chalkboard: $\frac{x+2}{x}+\frac{4}{x+2}=$

Teacher: What is the rule? I am going to add them; how do I do that?

Student: You need a common denominator

The students realise that they must find a common denominator, but they do not know how to find it. The teacher then writes the $\frac{1}{2}+\frac{1}{3}=$ on the chalkboard and asks, "What do I have to do here?" The students know straight away how to find the common denominator in this task. He then returns to the first two fractions.

Teacher: Here, then?

Student: The same.

The teacher tries to draw on the students' previous knowledge about adding number fractions to help them add fractions with unknowns. He tries to show them that the procedure is the same, even though there are x-es involved. The students see the connection, but they are still not sure how to do it. The 
teacher refers to "the rule" and does not ask for justification, which points toward procedural knowledge. On the other hand, this is something the teacher expects the students to know already, and he is trying to relate it to what they are currently working on to help students see connections between mathematical topics.

The focus on isolated procedural and factual knowledge exemplified above does not indicate a focus on developing ML.

\section{Contexts}

Most of the activities and tasks in the observed lessons do not contain any contexts. They are used to practise procedures and skills. That is, they focus on mathematical knowledge and therefore are less concerned with developing ML.

However, in the last part of teacher A's lesson 5 and the first part of lesson 6, and teacher B's last parts of lessons 1 and 2, they focus specifically on solving word problems using equations. The lesson topics are "Equations and problem solving" (A) and "From text to equation" (B). The topics indicate that the solution method (equations) is the real focus and not the problem situation.

The word problems contain contexts connected to personal and social life. Teacher A used tasks from the textbook, such as:

Hanna buys 5 pizzas and 10 soft drinks for a class party. The total cost is 650 NOK. How much does one pizza cost if one soft drink bottle costs 18 NOK? Solve the task by equations. (Hjardar \& Pedersen, 2014a, p. 56)

The task context is authentic in the sense that it is likely that someone buys pizzas and soft drinks for a class party. However, the question and method are not authentic. If someone were arranging a class party, they would likely know the price of both the soft drink and the pizza before buying it. If not, they would look at the price list or ask the cashier.

Teacher B displays the tasks on a PowerPoint slide. They are not collected from the textbook, but the structure is similar. For example:

The ages of two brothers and a sister add up to 35 years. The oldest brother is twice the age of the sister. The youngest brother is three years older than the sister is. Altogether, they have 12 arms and legs. How old are each of them? (Teacher B, lesson 1.)

Here, context and question are authentic. It is common wanting to know someone's age. However, usually when asking, one will get the answer straight away. Hence, the method is not authentic. Other examples of contexts concern finding an amount of money, or the number of fish caught. In general, the contexts are (at least to some extent) authentic, but questions and methods are not. There are no certifications.

On some occasions, the teachers use contexts to help students understand how to perform calculations. For example, in teacher A's lesson 4, a student is unsure how to calculate $-3 x+5 x$. Teacher A says: " $\mathrm{X}$ is chocolate bars. You owe me three chocolate bars. You get five from your mother. How many do you have left?" Nothing about this context is authentic. Indicating that $x$ is a subject may damage students' conceptual understanding and cause misconceptions related to students' mathematical knowledge.

In lesson 1, teacher $C$ uses the context of debt when explaining subtraction of negative numbers to a student who is unsure how to perform the calculation: "You lack five kroner, and then you lack one 
more. How much do you lack then?" She constructs a narrative to fit the symbolic expression. The lack of money is not unusual. In this case, the lack is not connected to a specific situation, and it is difficult to evaluate authenticity. The teacher uses the context to support the student's understanding of negative numbers and mathematical knowledge.

Teacher C's three lessons on percentages contain everyday life contexts. The tasks concern situations from personal and social life. They concern sale and discount, salary increase, and comparison of prices, for example, in lesson 3:

Anne's annual salary increased from 276000 NOK to 285400 NOK. How many per cent was the salary increase? (Bakke \& Bakke, 2006, p. 114)

In this task, context, question, and method are authentic. However, it is sometimes more interesting to know the amount rather than the per cent, at least from a personal point of view.

In the observed lessons, issues of authenticity concerning the contexts are only commented on two occasions, both in teacher B's classroom. In a task about a pasture (which will be sited in the Tools section), the teacher comments that "This is a problem that many horse owners have", in a humorous tone, followed by laughter, suggesting that this is just a joke. Also, in lesson 1, after obtaining the answer to a task about the price of a pack of chewing gum, a student comments to the teacher that "Chewing gum is not that cheap". These two comments are not subject to further discussion, suggesting that realworld aspects are not of real concern.

In lesson 4 , teacher $C$ refers to a discussion they had earlier about Black Friday sales. She talks about how to use percentages to evaluate if it is a good buy. She also talks about a web page that compares prices on commodities in different stores. This web page contains graphs that show how the prices have changed, and the teacher explains how this helps evaluate a buy. In lesson 5 , teacher $C$ talks about two newspaper articles, one that compared prices in general stores and another that compared the municipal taxes in neighbouring municipalities. She uses these newspaper articles as examples of how comparisons of percentages are used in personal and social contexts. In both these examples, the teacher provides certification of how percentages are used in daily life. However, the teacher is doing most of the talking, and there are few opportunities for the students to explore the contexts themselves.

\section{Dispositions}

To help students develop positive dispositions, the teachers rely heavily on communication. They talk to the students about how they are doing, praise them, and try to encourage and motivate them. For example, at the end of a conversation with the students, they very often say "good" or "well done". In lesson 3, teacher B comments to the class that

I think that the way you work now, that you discuss, you compare, you stop when you feel that "I cannot get any further, this cannot be right, something's wrong here". It is excellent, the way you work now. No-one is sitting there and just "I don't know anything about this".

The teacher is commenting on their strategic competence, which complies with what he expects of them. He wants them to be confident, to reflect on what they do, and not give up if the first strategy does not work.

The teachers try to encourage students if they are frustrated, like teacher B in lesson 1: A student asks for help, thinking that she is unable to solve the task. She erases what she has written and solves the task again with the teacher standing beside her. She discovers that what she had erased was correct and says, "That is in fact, what I had written." The teacher replies, "Yes, it is exactly what you had 
written. I have said it before; you have to trust yourself!" Similarly, teacher A comments: "You know, the point is that if you sit down and think that 'This is too difficult, I will never make it, this will never work', then you get negative thoughts, and then it gets difficult."

Teacher A encourages the students to come to the chalkboard and show their solutions. By agreeing to share their solutions in front of the whole class, the students show confidence in the work they have done. Also, focusing on the students' solutions may serve as an inspiration for the rest of the class. It may also be a factor in developing an inclusive class environment. The students take risks by showing their solutions to the rest of the class, but the students' methods may open up for further discussions on the topic, for example, if the solution on the chalkboard contains an error, like in teacher A's lesson 4: A student instructs the teacher how to solve the equation $64=4 x^{2}$, and gets the answer $x= \pm 4.24$. When they test the answer, the left side is not equal to the right, and they conclude that the solution must be wrong.

Teacher: What do we do? If these two are not equal? If I gave you a test and you got this answer, what would you do? What would you do?

Student: Try again.

Teacher: Try again. How many of you would think that 'Oh, I cannot do it', and moved on to the next task, without trying again? How many of you would do that?

In this situation, the teacher tries to focus on flexibility. If the solution is wrong, the students need the confidence to try again and flexibility to adapt the method to get it right. The students also need to see that there is nothing wrong with not getting it right the first time as long as they do not give up. Not giving up is also connected to strategic competence.

Teacher C's comments regarding Black Friday sales and the local taxes referred in the previous section are also ways to foster positive dispositions toward ML. Trying to relate to students' interests and give examples of how mathematics is used in everyday life may help them to see mathematical knowledge as something useful and worthwhile and motivate them to engage in the subject.

As mentioned earlier, the teachers spend much time demonstrating tasks on the chalkboard. Procedural fluency may contribute to developing students' confidence in mathematics because it provides them with a strategy for obtaining the correct answer. Hence, demonstrating tasks to develop procedural fluency is also a way to develop positive dispositions.

Tools

Communication is an important tool in the teachers' lessons. The teachers talk a lot, explaining concepts and demonstrating procedures. In this way, language serves as a tool to mediate mathematical knowledge. Particularly teacher B stresses that students should discuss with each other. He encourages the students to talk about what they are doing. When they are working individually, he approaches them and tells them to talk. However, the talk mainly concerns procedural steps and what to do next to solve the tasks. The students are not asked to justify or explain procedures to each other. Therefore, it seems as if the talk is oriented towards developing students' mathematical knowledge. Also, talk may support students' positive dispositions. Students may become more motivated by being allowed to work together. It can also be easier to ask questions or demonstrate the solution to the whole class if the problem has been discussed with a peer first.

There are examples from all three teachers where they use drawings in their modelling of a task solution. The drawings serve as representational tools to mediate thinking to represent the situation with symbols and to solve the equation. The example below is from teacher B's lesson 2. 
In a pasture, the length is three times the breadth. The perimeter is 240 meters. What is the area of the pasture?

A group of students start discussing how to solve the task. The teacher says, "Here we have to start with discussing the geometrical figure. It may be smart to make a drawing." He walks around the classroom listening to the students' discussions. He sits down with two students

Teacher: We have a pasture, and it has length and breadth. What figure is that?"

Student: Rectangle.

Teacher: (Nods) Draw a rectangle. (The students draw a rectangle.) What is the length and what is the breadth? (The student points on the drawing). If the breadth is $x$, what is the length?

Student: Three $\mathrm{x}$.

The teacher has assisted the students in representing the task information with a drawing of a geometrical figure. He directs the students' attention to the length of the perimeter and suggests that they start discussing the formula for finding the perimeter. Then he moves on to another group of students. The concepts breadth, length and perimeter refer to a shape, and the students must draw on their conceptual knowledge to connect the concepts with the figure. The drawing of the figure makes it easier to formulate the equation to solve the task.

The word problems are in themselves examples of representations. Here, a situation or problem is stated with written language. The students are supposed to represent the situation or problem using mathematical symbols. As mentioned, drawings can mediate students' thinking. However, a gradual process from written language to mathematical symbols is also possible, such as the following example in teacher A's lesson 6. The task is:

Three buckets have different colours and volumes. Five blue buckets have the same volume as three red buckets. Two yellow buckets and one blue bucket have the same volume as one red bucket. How many yellow buckets have the same volume as one blue bucket? Solve using equations. (Hjardar \& Pedersen, 2014b, p. 40)

The teacher says, "Five blue equals three red, and two yellow plus one blue equal one red." At the same time, she writes:

$$
\begin{aligned}
& 5 b=3 r \\
& 2 y+1 b=1 r
\end{aligned}
$$

"Five blue buckets" in the task is "five blue" in the teacher's oral representation and " $5 b$ " in her written mathematical symbols. "Have the same volume as" in the task is "equal" in the teacher's oral representation and is represented written with the equal sign. The symbols are expressed in natural oral language to structure the information given in the tasks. Gradually, they move towards formal mathematical notations to solve the task. Natural language serves as a tool to help the student formulate the task using mathematical symbols to solve it.

In lesson 6, teacher A demonstrates how to solve inequalities. She solves $x+4<8$ on the chalkboard. To mediate students' understanding of what the solution $x<4$ means, she draws a number line on the chalkboard: 


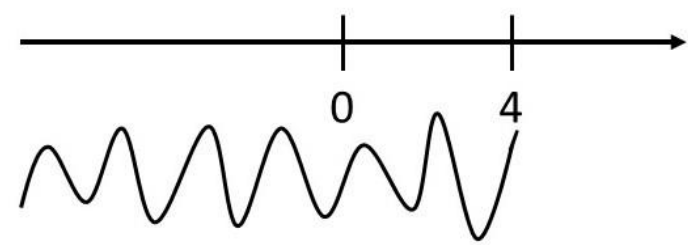

The number line is a representation of which the students are familiar. The intention is to help students understand the meaning of the solution, that is, to show that there are several values for $\mathrm{x}$, which makes the inequality true. The teacher is using the representation as a tool to develop their conceptual understanding and mathematical knowledge.

\section{Critical orientation}

The activities in the lessons mostly concern tasks without contexts. The tasks' focus is to develop procedural fluency. Therefore, the teachers do not emphasise the role mathematics plays in the world.

However, a few situations are worth mentioning (see also the Context section above). In lesson 4, on percentages, teacher $\mathrm{C}$ refers to an earlier discussion about Black Friday. She talks about the importance of knowing percentages to avoid being tricked by the stores. She explains how the stores often raise prices before the sales so they can advertise big discounts, and that it is smart to compare prices in different stores before buying.

In lesson 5, teacher $C$ refers to a newspaper article they had discussed earlier in social studies. The article compared municipal taxes in neighbouring municipalities. There were great differences between the municipalities, and they had discussed different reasons for this. The teacher did most of the talking, but with these two examples, she tries to show students how mathematical information is used to make decisions and judgements. In this way, critical orientation is, to some extent, involved in these two lessons. However, in general, the teachers do not pose open-ended questions concerning social, political, cultural, historical, environmental, or scientific issues for the students to analyse and reflect upon.

A summary of the results is presented in Table 2. In general, it seems that the main objective is to develop mathematical knowledge, and the other elements serve as a means to this goal. In the remaining part of the article, I discuss these results and make concluding remarks.

Table 2. Summary of results

\begin{tabular}{|c|c|}
\hline Element & Results \\
\hline Mathematical & The teachers explain and practice methods to develop procedural fluency. \\
\hline knowledge & $\begin{array}{l}\text { They try to connect concepts and representations. Teacher B introduces a } \\
\text { strategy for problem-solving, but students are not encouraged to develop } \\
\text { their own strategies. There are no observations where teachers include } \\
\text { non-routine problems or discuss or encourage the use of alternative } \\
\text { methods. They are also not observed requesting students' justifications } \\
\text { and explanations. }\end{array}$ \\
\hline Contexts & $\begin{array}{l}\text { Few tasks involve contexts. Task contexts from personal life are used, } \\
\text { mainly through traditional word problems. The task contexts are } \\
\text { authentic, but certifications are not observed. Some certified contexts are } \\
\text { provided by the teacher as examples and do not involve any observed } \\
\text { student activity. The task questions and methods are not certified and are } \\
\text { rarely authentic. }\end{array}$ \\
\hline
\end{tabular}




\begin{tabular}{|c|c|}
\hline Dispositions & $\begin{array}{l}\text { There is extensive use of praise and encouraging comments directed at } \\
\text { how students work and their task solutions, aimed to develop confidence. } \\
\text { Comments aimed at relating mathematics to students' interests are made. } \\
\text { Teacher enthusiasm and stimulation of students' curiosity are not evident. }\end{array}$ \\
\hline Tools & $\begin{array}{l}\text { The teachers use language to mediate knowledge. The teachers model and } \\
\text { encourage the use of visual representations. There is no observed use of } \\
\text { digital or physical tools. }\end{array}$ \\
\hline $\begin{array}{l}\text { Critical } \\
\text { orientation }\end{array}$ & $\begin{array}{l}\text { There is no evidence of numbers presented in and derived from word } \\
\text { problems being discussed, questioned, evaluated, or validated. Teacher C } \\
\text { talks about how mathematics is used to make decisions. However, there } \\
\text { are no observations where students are asked to use mathematical } \\
\text { information to make decisions and judgements, add support to } \\
\text { arguments, and challenge an argument or position themselves. }\end{array}$ \\
\hline
\end{tabular}

\section{Discussion and conclusions}

In this article, I study how teachers operationalise students' learning for ML in Grade 9 secondary school mathematics classes in terms of five elements. As noted in the outline of the ML model, the elements are closely connected. That means that one can be addressing several elements at the same time. This is also demonstrated in the previous section, where several examples involve more than one element. What seems to be recurring is the emphasis on mathematical knowledge. Contexts, dispositions, tools, and critical orientation appear to be mainly oriented towards developing aspects of mathematical knowledge, and not so much for the development of knowledge of contexts, dispositions, tools and critical orientation. The findings support those by Gainsburg (2008), suggesting that teachers' main focus is to impart mathematical concepts and skills.

Previous research has demonstrated that teachers relate teaching for ML to teaching the use-value of mathematics through problem-solving tasks and practical tasks with contexts related to other curriculum subjects or everyday life (Bolstad, 2019; Genc \& Erbas, 2019). Teaching for ML involves the challenge of promoting students' mathematical knowledge at the same time as providing the conditions under which they learn to use mathematics in context. As summarised in Table 2, there is little emphasis on creating opportunities for students to learn to use mathematics in context. The few tasks that involve contexts use them merely as "window dressing" to practice a mathematical skill. Word problems in mathematics can, therefore, sometimes appear nonsensical, leading to jokes like "Maths, the only place people can buy 64 watermelons, and no one wonders why." Such issues affect students' dispositions. According to Vos (2018), students are more motivated by authentic questions than by authentic contexts. The contexts used in classrooms should, therefore, be selected with care to help students appreciate how understanding numbers and calculations can illuminate meaning in real life.

Teaching ML across the curriculum is emphasised by researchers (Geiger, Goos, \& Dole, 2014; Steen, 2001), teachers (Bolstad, 2019), and policymakers (The Norwegian Directorate for Education and Training, 2013). In the observed lessons, there is little evidence of such cross-curricular work. This may be surprising as the three teachers are all experienced professionals and they teach several other subjects where they could find suitable contexts. When investigating teachers' recognition of mathematics in museum exhibits, Popovic and Lederman (2015) found that the teachers searched for explicitly represented concepts such as numbers, graphs, and shapes. Only after instruction from the researchers they started looking for exhibits that would make abstract mathematical concepts more concrete. In the same way as for students, we cannot expect teachers to make real-world connections out of the blue. Hence, the lack of meaningful contexts in the observed lessons may be explained by teachers' lack of experience with how to teach mathematical knowledge in meaningful contexts for 
example through a cross-curricular approach (Steen, 2001) or mathematical modelling activities (Blum \& Ferri, 2009).

Another related point involves the use of textbooks. Practical non-textbook tasks, problem-solving, mathematical modelling, and open-ended problems are related to ML development (Blum et al., 2007; Bolstad, 2019; Genc \& Erbas, 2019; Kaiser \& Willander, 2005; The Norwegian Directorate for Education and Training, 2013). The teachers in the study rely heavily on the textbook, and the students spend most of the time practising textbook tasks. These tasks do not fall under the categories of problemsolving or modelling. Although textbook tasks may provide opportunities for engagement in meaningful contexts, it requires that the teacher takes these opportunities. For example, the task about salary increase referred in the Observations section does not show meaningful use of mathematics. It only serves to practice mathematical skills. Discussing the reasons for posing such a question could provide meaningful reflections on issues from real life. For example, a person could find it interesting to calculate the percentage salary increase to compare it with the national average and retail price index. A comparison of salary increases may lead to investigations concerning who gets the larger increase, and what is fair. These kinds of investigations and discussions involve social, political, and environmental issues. By focusing on such issues, students get the opportunity to understand how numbers can both conceal and reveal descriptions of the world. Such understanding is connected to critical orientation.

In the ML model, all the elements are grounded in critical orientation, making critical orientation an overarching construct. Critical orientation is hence an important part of using mathematics in contexts. Critical orientation and contexts appear to be the most challenging elements to implement (see Table 2). Geiger, Forgasz, et al. (2015) also report that implementing activities that integrate a critical orientation is challenging. Their research shows that teachers struggled with this, even after two years of engagement with the idea, despite an indication from the teachers that developing a critical orientation is an important goal for schooling and one worth pursuing. So, even when there is a desire to embed a critical orientation within ML tasks, time, opportunity, and experience are still necessary to develop rich tasks that best support the implementation of this aspect. It is therefore not surprising that the teachers in my study did not integrate critical orientation in their lessons. Critical orientation involves complex and demanding issues, both for the teacher and the students because mathematics in real life are not as black and white as in traditional word problems in textbooks.

The heavy reliance on textbooks may also be connected to the lack of experience with cross-curricular and modelling tasks discussed earlier. In addition to the real-life aspect of such tasks, they also involve unpredictability and uncertainty. One never knows what issues or strategies students take up. The topics may be far from the teacher's knowledge area, and the mathematical content may not comply with the curriculum. Therefore, the textbook provides a structured and predictable plan that ensures that the curriculum content is covered.

The observed lessons involve a textbook guided and rather traditional teaching approach, which is different than what is recommended in the research literature on developing ML. Tanner and Jones (2013) confirm the difficulty teachers have in moving on from traditional teaching practices. Changing expectations of teaching and learning is complex, and it takes time. On the other hand, some teachers may not have the will or see the need to change practice. However, teaching for ML calls for something else than the traditional teaching of mathematics (Haara et al., 2017; Steen, Turner, \& Burkhardt, 2007). The inclusion of real-world problems and a cross-curricular approach requires a different way of thinking about teaching. However, teachers feel that they do not have sufficient knowledge of how to work interdisciplinary (Bolstad, 2019) and how to teach modelling (Steen et al., 2007). Therefore, inservice teachers and pre-service teachers must get the necessary support in their professional 
development, for example, from professional development programmes and teacher education courses. In that respect, the ML model can serve as a useful tool for teachers in their planning.

Based on the analysis and observations reported in the previous section (see Table 2), the conclusion is that in the observed lessons, teachers' operationalisation of ML appears to be fragmented rather than integrated. Even though the ML elements are involved in the lessons, the connections between them are not apparent. In other words, the teaching is concerned with the elements in isolation and not holistically to develop ML. Students may develop competences connected to all five elements, but they are left to make the connections between the elements on their own, and as a result, to develop the ability to use mathematics in real-world situations on their own. In that sense, one can question whether the teachers are operationalising students' learning for ML. Several suggestions have been made in this article regarding possible reasons for teachers' challenges.

Teaching for ML requires an integrated approach, connecting the elements in mathematical activities. This does not necessarily require drastic changes from the teacher, but rather a slight move of emphasis and awareness.

\section{Closing remarks}

It is important to note that the research in this article is based on a few teachers' teaching in a limited number of lessons. The topics are also limited. Visiting these teachers at another time could have given a different result. The teachers' reflections regarding the lessons could also have provided a more nuanced picture of their teaching. Therefore, the analysis is not a characteristic of the teachers, but of the specific teaching in the specific classrooms at specific times as observed by me.

It is also important to emphasise that it is not expected that teachers teach across the curriculum or modelling all the time. Knowledge of procedures and facts are essential elements in mathematics education. The challenge is to connect these procedures and facts to the other elements to make teaching for ML more coherent and connected.

Therefore, there is a need for further research on how to assist teachers in implementing teaching for ML in mathematics classrooms. Research on teachers' understanding of ML and reflections on how to teach for it can be a starting point. A study of students' experiences of teaching for ML may also prove useful in this respect.

\section{References}

Aksu, G., \& Güzeller, C. O. (2016). Classification of PISA 2012 mathematical literacy scores using Decision-Tree Method: Turkey sampling. Egitim ve Bilim, 41(185), 101-122.

Areepattamannil, S. (2014). International note: What factors are associated with reading, mathematics, and science literacy of Indian adolescents? A multilevel examination. Journal of Adolescence, 37(4), 367-372. doi:10.1016/j.adolescence.2014.02.007

Bakke, B., \& Bakke, I. N. (2006). Grunntall 9. Matematikk for ungdomstrinnet [Digits. Mathematics for lower secondary school]. Drammen: Elektronisk undervisningsforlag AS.

Blikstad-Balas, M. (2017). Key challenges of using video when investigating social practices in education: contextualization, magnification, and representation. International Journal of Research \& Method in Education, 40(5), 511-523. doi:10.1080/1743727X.2016.1181162

Blikstad-Balas, M., \& Sørvik, G. O. (2015). Researching literacy in context: Using video analysis to explore school literacies. Literacy, 49(3), 140-148. doi:10.1111/lit.12037

Blum, W., \& Ferri, R. B. (2009). Mathematical modelling: Can it be taught and learnt? Journal of mathematical modelling and application, 1(1), 45-58.

Blum, W., Niss, M., \& Galbraith, P. (2007). Introduction. In W. Blum, P. Galbraith, H.-W. Henn, \& M. Niss (Eds.), Modelling and applications in mathematics education: The 14 ICMI study (pp. 3-32). New York: Springer

Bolstad, O. H. (2019). Teaching for mathematical literacy: School leaders' and teachers' rationales. European Journal of Science and Mathematics Education, 7(3), 93-108. 
Breakspear, S. (2012). The policy impact of PISA: An exploration of the normative effects of international benchmarking in school system performance. In OECD Education Working Papers No. 71. Paris: OECD Publishing.

Bryman, A. (2008). Social research methods (3rd ed.). Oxford: Oxford University Press.

D'Ambrosio, U. (2007). The role of mathematics in educational systems. The International Journal on Mathematics Education, 39(1), 173-181.

Frankenstein, M. (2010). Developing a criticalmathematical numeracy through real real-life word problems. In U. Gellert, E. Jablonka, \& C. Morgan (Eds.), Proceedings of the Sixth International Mathematics Education and Society Conference (Vol. 1, pp. 248-258). Berlin: Freie Universität Berlin.

Gainsburg, J. (2008). Real-world connections in secondary mathematics teaching. Journal of Mathematics Teacher Education, 11(3), 199-219. doi:10.1007/s10857-007-9070-8

Geiger, V., Forgasz, H., \& Goos, M. (2015). A critical orientation to numeracy across the curriculum. ZDM, 47(4), 611-624. doi:10.1007/s11858-014-0648-1

Geiger, V., Goos, M., \& Dole, S. (2014). Curriculum intent, teacher professional development and student learning in numeracy. In Y. Li \& G. Lappan (Eds.), Mathematics curriculum in school education (pp. 473-492). Dordrecht: Springer.

Geiger, V., Goos, M., \& Forgasz, H. (2015). A rich interpretation of numeracy for the 21st century: A survey of the state of the field. ZDM, 47(4), 531-548. doi:10.1007/s11858-015-0708-1

Genc, M., \& Erbas, A. K. (2019). Secondary mathematics teachers' conceptions of mathematical literacy. International Journal of Education in Mathematics, Science and Technology, 7(3), 222-237.

Goos, M., Geiger, V., \& Dole, S. (2010). Auditing the numeracy demands of the middle years curriculum. In L. Sparrow, B. Kissane, \& C. Hurst (Eds.), Shaping the future of mathematics education. Proceedings of the 33rd annual conference of the Mathematics Education Research Group of Australasia (pp. 210-217). Freemantle: MERGA.

Goos, M., Geiger, V., \& Dole, S. (2014). Transforming professional practice in numeracy teaching. In Y. Li, E. A. Silver, \& S. Li (Eds.), Transforming mathematics instruction: Multiple approaches and practices (pp. 81-102). Dordrecht: Springer International Publishing.

Haara, F. O., Bolstad, O. H., \& Jenssen, E. S. (2017). Research on mathematical literacy in schools - Aim, approach and attention. European Journal of Science and Mathematics Education, 5(3), 285-313.

Hiebert, J., \& Lefevre, P. (1986). Conceptual and procedural knowledge in mathematics: An introductory analysis. In J. Hiebert (Ed.), Conceptual and procedural knowledge: The case of mathematics (pp. 1-27). Hillsdale: Erlbaum.

Hjardar, E., \& Pedersen, J.-E. (2014a). Faktor 9. Grunnbok. Matematikk for ungdomstrinnet [Factor 9. Mathematics for lower secondary school]. Oslo: Cappelen Damm AS.

Hjardar, E., \& Pedersen, J.-E. (2014b). Faktor 9. Oppgåvebok. Matematikk for ungdomstrinnet [Factor 9. Work book. Mathematics for lower secondary school]. Oslo: Cappelen Damm AS.

Höfer, T., \& Beckmann, A. (2009). Supporting mathematical literacy: Examples from a cross-curricular project. ZDM, 41(1-2), 223-230. doi:10.1007/s11858-008-0117-9

İş Güzel, Ç., \& Berberoğlu, G. (2010). Students' affective characteristics and their relation to mathematical literacy measures in the Programme for International Student Assessment (PISA) 2003. Egitim Arastirmalari - Eurasian Journal of Educational Research(40), 93-113.

Jablonka, E. (2003). Mathematical literacy. In A. J. Bishop, M. A. Clements, C. Keitel, J. Kilpatrick, \& F. K. S. Leung (Eds.), Second International Handbook of Mathematics Education (pp. 75-102). Dordrecht: Kluwer Academic Publishers.

Jones, S., \& Tanner, H. (2008). Reflective discourse and the effective teaching of numeracy. Paper presented at the Proceedings of the Joint Meeting of PME 32 and PME-NA XXX, Morelia, Mexico.

Kaiser, G., \& Willander, T. (2005). Development of mathematical literacy: Results of an empirical study. Teaching Mathematics and its Applications, 24(2-3), 48-60. doi:10.1093/teamat/hri016

Kilpatrick, J., Swafford, J., \& Findell, B. (2001). Adding it up: Helping children learn mathematics. Washington: National Academy Press.

Maltese, A. V., Danish, J. A., Bouldin, R. M., Harsh, J. A., \& Bryan, B. (2015). What are students doing during lecture? Evidence from new technologies to capture student activity. International Journal of Research \& Method in Education, 39(2), 208226. doi:10.1080/1743727X.2015.1041492

Niss, M., \& Jablonka, E. (2014). Mathematical literacy. In S. Lerman (Ed.), Encyclopedia of Mathematics Education (pp. 391-396). Dordrecht: Springer.

Nordtvedt, G. A. (2013). Matematikk i PISA - matematikkdidaktiske perspektiver. In M. Kjærnsli \& R. V. Olsen (Eds.), Fortsatt en vei å gå: Norske elevers kompetanse i matematikk, naturfag og lesing i PISA 2012 (pp. 43-65). Oslo: Universitetsforl.

Noss, R., Hoyles, C., \& Pozzi, S. (2000). Working knowledge: Mathematics in use. In A. Bessot \& J. Ridgway (Eds.), Education for mathematics in the workplace (pp. 17-35). Dordrecht: Kluwer.

OECD. (2012). PISA 2012 Assessment and analytical framework. Mathematics, reading, science, problem solving and financial literacy. Retrieved from https://www.oecd.org/pisa/pisaproducts/PISA\%202012\%20framework\%20e-book_final.pdf

Popovic, G., \& Lederman, J. S. (2015). Implications of informal education experiences for mathematics teachers' ability to make connections beyond formal classroom. School Science and Mathematics, 115(3), 129-140. doi:10.1111/ssm.12114

Roth, W.-M., \& Radford, L. (2011). Cultural-historical perspective on mathematics teaching and learning. Rotterdam: Springer.

Schoenfeld, A. H. (2001). Reflections on an impoverished education. In L. A. Steen (Ed.), Mathematics and democracy: The case for quantitative literacy (pp. 49-54). Princeton: The National Council on Education and the Diciplines.

Sfard, A. (2014). Why mathematics? What mathematics? In M. Pitici (Ed.), The best writing on mathematics 2013. Princeton, NJ: Princeton University Press.

Skemp, R. R. (1976). Relational understanding and instrumental understanding. Mathematics Teaching, 77, 20-26. 
Skovsmose, O. (2011). An Invitation to Critical Mathematics Education. Rotterdam: SensePublishers.

Steen, L. A. (Ed.) (2001). Mathematics and democracy: The case for quantitative literacy. Princeton: The National Council on Education and the Diciplines.

Steen, L. A., Turner, R., \& Burkhardt, H. (2007). Developing mathematical literacy. In W. Blum, P. L. Galbraith, H.-W. Henn, \& M. Niss (Eds.), Modelling and Applications in Mathematics Education: The 14th ICMI Study (pp. 285-294). New York: Springer.

Tanner, H., \& Jones, S. (2013). Developing Mathematical Literacy in Welsh Secondary Schools. The Welsh Journal of Education, $16(1), 21-36$.

The Norwegian Directorate for Education and Training. (2012). Framework for basic skills. Oslo Retrieved from https://www.udir.no/contentassets/fd2d6bfbf2364e1c98b73e030119bd38/framework_for_basic_skills.pdf

The Norwegian Directorate for Education and Training. (2013). Curriculum for the common core subject of mathematics. Oslo: Ministry of Education and Research Retrieved from https://www.udir.no/k106/MAT104?lplang=http://data.udir.no/kl06/eng

Tzohar-Rozen, M., \& Kramarski, B. (2013). How does an affective self-regulation program promote mathematical literacy in young students? Hellenic Journal of Psychology, 10(3), 211-234.

Vos, P. (2018). "How real people really need mathematics in the real world" - Authenticity in mathematics education. Education Sciences, 8(4), 195-208.

Wedege, T. (1999). To know or not to know: Mathematics, that is a question of context. Educational Studies in Mathematics, 39(1/3), 205-227. 